\title{
Os Estudos de Segurança na Turquia: Situando a Turquia no "Ocidente" meio de "Escrever a Segurança"l"*
}

Pinar Bilgin**

Escrevendo sobre estudos estratégicos e Terceiro Mundo, Baghat Korany (1986) aponta para a crescente irrelevância dos conceitos e teorias tradicionais de Relações Internacionais para o mundo em desenvolvimento. A observação de Korany também seria válida para o contexto turco? A literatura sobre Relações Internacionais na Turquia nem sempre foi explícita acerca da limitada relevância dos conceitos e teorias tradicionais de Relações Internacionais para o contexto turco. Ocasionalmente, o leitor depara-se com passagens afirmando ser a teoria realista de Relações Internacionais mais apropriada que as demais para explicar as políticas externa e de seguran-

\footnotetext{
* A frase "escrevendo a segurança" (writing security) é de Campbell (1992). Artigo recebido e aceito para publicação em abril de 2004. Tradução de Carolina Moulin. Uma versão preliminar deste artigo foi apresentada na Conferência Anual da Associação de Estudos Internacionais em Montreal, Canadá, 17-20 de março de 2004. A autora gostaria de agradecer a Mônica Herz pelos comentários e a Berivan Elis pela assistência de pesquisa.

** Professora do Departamento de Relações Internacionais e assistant dean da Faculdade de Economia, Administração e Ciências Sociais da Universidade de Bilkent, Ankara, Turquia.
}

CONTEXTO INTERNACIONAL Rio de Janeiro, vol. 26, no 1, janeiro/junho 2004, pp. 149-185. 
ça da Turquia (Tayfur, 1999:75). Mas, em geral, o que há é uma reflexão limitada, embora crescente, sobre o tema ${ }^{1}$. Contudo, isto não significa que não exista uma disjunção entre teorias e conceitos tradicionais de segurança e os problemas e políticas turcos. Ao contrário, a Turquia tem compartilhado grande parte das preocupações enfrentadas por vários outros países em desenvolvimento, tais como sobre a construção do Estado, o estabelecimento de sistemas seguros de energia, finanças e comércio, provisão de alimentos, moradia, serviços de saúde e educação para uma população em crescimento, bem como com o poder militar dos vizinhos. A concepção de "segurança nacional" orientada para o plano externo e focalizada militarmente não se mostra apropriada quando aplicada a tais preocupações, que têm caráter não-militar e que partem de dentro das fronteiras estatais.

A questão que este artigo tenta responder é em que medida a literatura de Relações Internacionais na Turquia tem tratado o tema da limitada relevância dos conceitos e teorias tradicionais de Relações Internacionais para lidar com as preocupações turcas. Procurar-se-á mostrar que durante grande parte da Guerra Fria houve uma reduzida reflexão sobre esse assunto. $\mathrm{O}$ artigo sugere que isso está associado à preocupação política prevalecente no período, qual seja, a de situar a Turquia firmemente no "ocidente".

Isto não quer dizer que os trabalhos sobre segurança simplesmente respondem ao e refletem o ambiente externo, já que nunca são politicamente neutros; eles ajudam a constituir o mundo à sua própria imagem. Contudo, esses estudos negam seu status interpretativo, pois propugnam "representar o drama da política internacional como um espetáculo inteligível sem interpretação" (Ó Tuathail e Dalby, 1998:6). Mediante análise dos escritos sobre segurança na Turquia, este artigo procura apontar para "a política auto-constitutiva" dessa literatura. Os escritos sobre segurança nesse período, como sugiro aqui, servirão para localizar a Turquia no "ocidente", por intermédio da repre- 


\section{Os Estudos de Segurança na Turquia:}

Situando a Turquia no "Ocidente"...

sentação das preocupações turcas enquanto aspectos de "segurança ocidental", isto é, com referência aos interesses e políticas de segurança dos Estados Unidos e de outros aliados da OTAN. Do mesmo modo, houve pouca, senão nenhuma, discussão sobre as preocupações de segurança turcas enquanto preocupações típicas do mundo em desenvolvimento. Isso aconteceu porque as referidas preocupações de afirmar a Turquia no ocidente não permitiram o reconhecimento de que parte das inseguranças turcas poderia ter suas raízes em seu caráter de país subdesenvolvido. A questão, portanto, é que, durante esse período, a representação da Turquia como "parceira júnior" dos Estados Unidos na luta contra o comunismo não ajudou a reproduzir sua identidade ocidental, além do que embasou a produção dos trabalhos sobre segurança na Turquia.

Foi nos anos 60 e 70, em seguida ao início dos problemas com Chipre (momento em que os tomadores de decisão turcos começaram a sentir as repercussões da alienação para com o restante do mundo em desenvolvimento) e, em especial, durante a détente (que coincidiu com o difícil período das relações turco-norte-americanas causado pelo questionamento da política externa turca após a intervenção em Chipre e o embargo de armas), que os acadêmicos turcos começaram a questionar a relevância da estrutura de "segurança ocidental" em relação às inseguranças turcas. Foi também nessa época que a produção teórica sobre segurança na Turquia começou a surgir. Entretanto, a questão da limitada importância da estrutura de segurança ocidental para lidar com as inseguranças da Turquia foi quase sempre explicada tendo como referência as características singulares da Turquia, e não seu status de país em desenvolvimento ${ }^{2}$.

A virada crítica seguinte na literatura sobre segurança na Turquia aconteceu na década de 90 e foi desencadeada pelo processo de adesão à integração européia. Foi nesse período que a concepção de segurança que moldava as políticas turcas começou a ser questionada na esfera pública, bem como nos escritos sobre o tema. Naquele mo- 
mento, emergiu também um debate, em alguma medida emudecido, sobre a concepção de "segurança nacional" na Turquia. Enquanto um grupo de autores apontava para a concepção de segurança subjacente às políticas turcas como um obstáculo no caminho da integração à União Européia, outros enfatizavam a discrepância entre a concepção de segurança da União Européia e a da Turquia e clamavam pela manutenção da concepção turca. Este último grupo era apoiado pela SAREM, o centro do pensamento das Forças Armadas turcas, que organizou uma conferência internacional em maio de 2003 para discutir a questão (SAREM, 2003). Foi também nessa época que o número de estudos que teorizavam as experiências turcas começou a crescer.

O artigo está dividido em três partes. A parte I discute o tema da disjunção entre os conceitos e teorias de Relações Internacionais e as realidades do Terceiro Mundo, enfatizando a importância do contexto histórico para a compreensão de como e por que algumas teorias viajam entre mundos. A parte II analisa como essa questão da limitada relevância dos conceitos e teorias tradicionais de segurança foi tratada nos escritos sobre segurança na Turquia durante a Guerra Fria. A parte III analisa os debates dos anos 90 sobre a concepção turca de "segurança nacional".

\section{Parte I}

Os analistas têm enfatizado há muito a limitada utilidade dos conceitos e teorias "ocidentais" para a compreensão e explicação das dinâmicas de segurança no resto do mundo (Thomas, 1987; Saravanamuttu e Thomas, 1989; Al-Mashat, 1985; Ayoob, 1986; 1995; Korany, 1986; Sayigh, 1990; Holsti, 1992; 1996). Caroline Thomas (1989) identificou a relação entre o mundo em desenvolvimento e os conceitos tradicionais de Relações Internacionais como sendo um "casamento infeliz" e chamou a atenção para a necessidade de se pedir o "divórcio". A conclusão é que o mundo em desenvolvimento 


\section{Os Estudos de Segurança na Turquia:}

Situando a Turquia no "Ocidente"...

deveria ser analisado lançando-se mão de conceitos e teorias diferentes, tendo como base suas próprias experiências. Isto porque, segundo Thomas, as preocupações de segurança dos Estados em desenvolvimento envolvem a construção do Estado, o estabelecimento de sistemas de alimentação, saúde, finanças, comércio, bem como o fortalecimento militar. Brian L. Job (1992) vai além e argumenta que manter a segurança contra ameaças que vêm de fora das fronteiras estatais é uma preocupação menor para os Estados em desenvolvimento, cujas fronteiras são mantidas por normas sociais internacionais (notadamente, os princípios da soberania, da inviolabilidade das fronteiras e de não-intervenção), enquanto as ameaças que vêm de dentro das fronteiras dominam a agenda de segurança governamental. Considerando esse ambiente, argumenta Job, a metáfora do "dilema de segurança" esconde mais do que revela; o "dilema de insegurança" explicaria melhor os problemas dos Estados em desenvolvimento. Visto desta maneira, o conceito de "dilema de insegurança" proposto por Job constitui um exemplo do que Thomas sugerira: novos conceitos derivados das experiências do mundo em desenvolvimento. Outros exemplos incluem as "guerras de terceiro tipo" (Holsti, 1996), "lado software da segurança nacional" (Azar e Moon, 1988), "balanço constante" (David, 1991) e "realismo subalterno" (Ayoob, 2002) ${ }^{3}$.

É importante notar que apesar das reservas daqueles que apontam para a limitada capacidade explicativa dos conceitos tradicionais, como "segurança nacional", para o contexto do mundo em desenvolvimento, estes tiveram enorme valor político para os "projetos de segurança nacional" (Pasha, 1996:284) das elites governantes, que usaram da linguagem da "segurança nacional" ao perseguirem políticas destinadas ao fortalecimento do Estado e/ou do regime de segurança.

Aqui, uma distinção deve ser feita entre reconhecer a limitada relevância da "segurança nacional" para a análise das inseguranças do 
mundo em desenvolvimento e chamar a atenção para a adoção de uma noção de segurança mais abrangente na análise e ser crítico dos governos que adotam uma ampla agenda de segurança e "securitizam" (Waever, 1995) várias questões em nome da "segurança nacional". O primeiro é uma instância analítica (com implicações normativas), enquanto o último é uma instância política (que enfatiza os problemas gerados quando os governos ampliam suas agendas de segurança e analistas alargam suas concepções de segurança) (ver idem; Huysmans, 2002). Citando Buzan, o problema aqui é que:

“[...] usar o termo [segurança nacional] com relação a Estados fracos, como se tais Estados representassem o mesmo tipo de objeto que um Estado forte, simplesmente abre caminho para a importação completa dos imperativos de segurança nacional na arena política doméstica, com todos os perigos da violência legítima que ela envolve. A segurança dos governos começa a se confundir com a segurança dos Estados e interesses fictícios adquirem um grau de legitimidade do qual não são merecedores" (1991:102).

Assim considerada, a migração do conceito de "segurança nacional" para o mundo em desenvolvimento pode ser vista como tendo auxiliado na constituição daqueles Estados (de segurança nacional) que, por seu turno, criam inseguranças para suas populações. Tais inseguranças aparecem às vezes sob a forma de políticas repressivas e supressão dos direitos e liberdades democráticos (Al-Mashat, 1985). Em outras ocasiões, elas tomam a forma de sacrifícios requeridos da população (como a tolerância de baixos níveis de investimento em saúde e educação como decorrência do financiamento ao fortalecimento militar) até que o imediatismo da ameaça à segurança nacional desapareça. Um tanto ironicamente, o conceito de "segurança nacional" deixa a desejar para os analistas que buscam tratar um maior leque de inseguranças geradas por esses mesmos "Estados de segurança nacional".

A questão mais ampla aqui envolvida se refere à discussão de "como o conhecimento no campo das Relações Internacionais chega ao Ter- 


\section{Os Estudos de Segurança na Turquia:}

Situando a Turquia no "Ocidente"...

ceiro Mundo, quais teorias 'viajam`e quais não, e as maneiras pelas quais o próprio conhecimento é transformado nesse processo" (Tickner, 2003:326) não podem ser conduzidos isoladamente da discussão sobre o contexto histórico no qual esses processos acontecem. Foi o contexto da Guerra Fria que permitiu que conceitos e teorias norte-americanas viajassem para o mundo em desenvolvimento, por via de generosas bolsas de estudo concedidas a estudantes e jovens acadêmicos, bem como a políticos em potencial, para que visitassem os Estados Unidos e aprendessem sobre a maneira "americana" de fazer Relações Internacionais (teoria) e relações internacionais (prática).

O contexto histórico que permitiu que a "segurança nacional" obscurecesse outras dimensões da segurança nos âmbitos político e acadêmico ${ }^{4}$ também forneceu as condições para sua migração para locais não-ocidentais. Especialmente nos contextos em que o processo de construção de políticas governamentais seguia a liderança dos Estados Unidos na Guerra Fria (como é o caso da Turquia), os conceitos e políticas norte-americanos foram recebidos de maneira menos crítica do que em outros (como na Índia e no Egito), onde as lideranças políticas questionavam abertamente a relevância da plataforma de segurança da Guerra Fria para o mundo em desenvolvimento (sobre a Índia, ver Muppidi, 1999; sobre o Egito, ver Nasser, 1955).

Nesse sentido, Ole Waever (1998:694) mostra que o desenvolvimento das Relações Internacionais em diferentes partes do mundo foi influenciado pela orientação de política externa daquele país (dentre outros fatores). Ao que se segue, baseando-se na análise do caso turco, o artigo sugere que o "contexto doméstico" deve ser acrescentado à lista de fatores que influenciam o desenvolvimento do estudo de Relações Internacionais em diferentes partes do mundo. O ponto central sendo que, no mundo em desenvolvimento, na medida em que a política externa responde tanto às ameaças domésticas quanto às externas, também os estudos em Relações Internacionais são moldados quer pelo contexto internacional, quer pelo doméstico. Um 
breve olhar sobre o uso do conceito de "segurança nacional" na Índia e no Paquistão fornece maior suporte a essa sugestão preliminar. Mustapha Kamal Pasha aponta que a "segurança nacional" serve a diferentes propósitos em diferentes contextos:

"No caso indiano, provê a base para a construção de uma ordem hegemônica regional; no caso do Paquistão, provê a razão de ser daquele país como um domínio separado. Dados esses dois significados, verifica-se que a 'segurança nacional' é correlacionada a diferentes articulações do espaço político na região. Na linguagem gramsciana, o projeto de segurança nacional no Paquistão serve aos propósitos de legitimação, embora não de maneira bem-sucedida. Ao contrário, a Índia tem procurado a liderança regional em nome da segurança nacional" (1996:285).

No caso da Turquia, a principal função política da "segurança nacional" tem sido consolidar a idéia, as instituições e as bases físicas do Estado (especialmente durante o início do período republicano) e defender a ideologia do Estado (contra o comunismo durante a Guerra Fria e o islamismo no pós-Guerra Fria).

Isso não quer dizer que somente o contexto histórico moldou a produção acadêmica sobre segurança. A divisão de trabalho na Guerra Fria entre generalistas e especialistas também foi fator influente nesse sentido. Constitutiva dessa divisão de trabalho disciplinar foi a premissa de que os estudos temáticos serviam meramente à compilação de dados para o teste das teorias que eram desenvolvidas tendo por base os padrões históricos do ocidente ${ }^{5}$. Esperava-se que os acadêmicos, estudando o mundo em desenvolvimento (chamados especialistas de área), adotassem os conceitos e teorias criados pelo e para o mundo em desenvolvimento, embora não fossem encorajados a questionar a limitada relevância desses conceitos e teorias em suas análises. Isso deriva da largamente aceita afirmação de que generalistas disciplinares produzem "conhecimento social universal baseados na busca por leis gerais de comportamento social" (Taylor, 1996:1921), enquanto especialistas de área aplicam as referidas teorias e modelos a regiões particulares. Também assentados sobre essa 


\section{Os Estudos de Segurança na Turquia:}

Situando a Turquia no "Ocidente"...

divisão de trabalho disciplinar (que produzia uma hierarquia entre generalistas e especialistas), os estudantes de Relações Internacionais eram levados a pensar que "o único modo de se engajar na política e na história de regiões do mundo era aquela que permitisse fazer dessas regiões instâncias particulares das histórias universais contadas sobre e no ocidente" (Mitchell, 2003:169). Essa divisão de trabalho e a hierarquização entre estudos de área e as disciplinas empobreceram tanto os especialistas - que freqüentemente rejeitavam as categorias universais, acentuando as singularidades das dinâmicas regionais e deixando intocadas as premissas não problematizadas acerca das diferenças entre o local e o global - quanto "a maneira pela qual essa distinção atribuiu a determinados fenômenos uma essência universal, uma racionalidade e uma energia, ao mesmo tempo que concedia a outros fenômenos um caráter meramente estático, reativo ou "cultural"(ibidem).

Isso não quer dizer que os conceitos e teorias desenvolvidos no ocidente sejam totalmente irrelevantes para o mundo em desenvolvimento. Por exemplo, do começo dos anos 60 em diante, uma literatura acerca das inseguranças do Terceiro Mundo começa a emergir. Entretanto, com sua ênfase sobre conflitos de baixa intensidade e "guerras de guerrilha" (Holsti, 1998:27), essa literatura tratava a questão da insegurança no mundo em desenvolvimento da perspectiva dos Estados desenvolvidos, focando, portanto, nas necessidades e interesses de segurança destes últimos. Nos trabalhos acadêmicos, os Estados em desenvolvimento eram enquadrados em um dos dois papéis disponíveis: ou eles eram considerados parte do "paradigma estabelecido e aceitavam o papel de parceiros juniores no jogo de poder" ou eles eram etiquetados como "causadores de problemas", estimulados pelo "poder de causar ruído/fazer barulho", feitos para o exercício de técnicas de "contra-insurgência" (Korany, 1986:549) ${ }^{6}$.

Na mesma medida, a literatura sobre segurança regional enfatizava as preocupações e os interesses de segurança dos Estados ocidentais, 
particularmente dos Estados Unidos. As implicações desse viés ocidental do pensamento sobre segurança no contexto do Oriente Médio eram de que muito do que fora produzido e feito sobre segurança regional no Oriente Médio estava baseado em concepções ocidentais sobre "segurança" (e "região") (Bilgin, 2004a). Durante a Guerra Fria, o que se queria dizer ao falar sobre "segurança no Oriente Médio" era a manutenção dos interesses de segurança ocidental (prioritariamente norte-americana) nesta parte do mundo e sua defesa militar contra atores externos (tal como a União Soviética, que podia colocar em risco o status quo regional e/ou global). Aos interesses e necessidades de segurança dos Estados regionais (sem falar de atores não-estatais) não era dada a devida atenção (Bilgin, no prelo-b). Isso, por conseguinte, empobreceu a literatura sobre segurança regional, na medida em que "a dinâmica de segurança regional e os problemas de segurança não foram incorporados nas análises teóricas da área" (Holsti, 1998:28) ${ }^{7}$.

Apontar para a necessidade de olhar para o contexto histórico dentro do qual os conceitos e teorias viajam entre mundos não significa sugerir que o contexto determina a substância. Como mantém K. J. Holsti,

"O estudo da política internacional nos anos da Guerra Fria - grosso modo, entre o fim dos anos $40 \mathrm{e}$ o final dos anos 80 - refletia as prioridades nacionais e os problemas de segurança, mas, à exceção de disfarces políticos explícitos, ele não estava subordinado às manchetes diárias. Havia um diálogo disciplinar dentro da academia que era abastecido pelos debates acerca da adequação dos conceitos, da metodologia e dos propósitos intelectuais" (idem:17; ver, também, Holden, 2002).

De maneira mais precisa, a questão é que o contexto molda a produção acadêmica ao impor limites sobre o que é estudado e como o estudo deve ser feito. A adoção de uma perspectiva centrada nos Estados nos estudos de segurança, por exemplo, foi feita na tentativa de introduzir maior organização e clareza à complexidade de se analisar 


\section{Os Estudos de Segurança na Turquia:}

Situando a Turquia no "Ocidente"...

fenômenos internacionais para os propósitos de construção de uma disciplina "científica" (nos moldes das ciências naturais) capaz de produzir o tão necessário aconselhamento político para a contenção do expansionismo soviético. Assim, os acadêmicos tentaram criar um "sistema fechado" (Smith, 1998:41-46), identificando os Estados como os atores mais significativos, presumindo serem eles unidades similares e focando na dimensão militar da segurança. Isso foi feito não só porque a complicada tarefa de lidar com indivíduos não poderia produzir o tipo de análise ordenada requerida por uma "ciência" de estudos sobre segurança, mas também porque a percebida urgência das preocupações da Guerra Fria tornara difícil qualquer engajamento com as análises complexas que um estudo de populações (indivíduos e grupos sociais) requereria (Tickner, 1997:618) ${ }^{8}$.

Uma vez ressaltada a significância do contexto histórico para a compreensão de como e por que as Relações Internacionais se desenvolvem diferentemente em distintos conjuntos, a próxima parte do artigo irá se voltar para o caso da Turquia.

\section{Parte II}

Embora o ensino de ciência política tenha uma longa história na Turquia, o estudo de Relações Internacionais é relativamente recente. A Faculdade de Ciências Políticas da Universidade de Ancara (Mulkiye) é a mais antiga de seu gênero e foi fundada em Istambul, em 1859, com o objetivo de treinar burocratas do alto escalão para a administração otomana. Mulkiye tomou como modelo as instituições francesas da época e seu currículo (formado por cursos de história, direito internacional, direito dos tratados, direito administrativo e economia) refletia os propósitos para os quais fora criada: contribuir para os esforços de evitar o declínio do império (Aybay, 1977). A escola transferiu-se para Ancara após a fundação da República (1923) e foi integrada à Universidade de Ancara em 1950. Este último desdobramento coincidiu com a busca turca por relações mais próximas com o 
"ocidente" e a crescente influência dos Estados Unidos sobre as instituições turcas.

"A vida acadêmica não era exceção a isso e a educação tradicional de ciência política (nos moldes franceses) perdeu considerável terreno para o estilo norte-americano de ciência política. Vários professores e jovens acadêmicos da Faculdade de Ciências Políticas foram estudar nas universidades norte-americanas com bolsas norte-americanas e, quando de seu retorno, traziam consigo novas idéias e métodos inspirados pela visão de mundo estadunidense" (idem:16).

Uma dessas idéias foi a criação do curso de Relações Internacionais. O primeiro curso intitulado "Relações Internacionais" entrou no currículo da Faculdade de Ciência Política em 1956 (Ataov, 1961:189), tendo sido conscientemente desenhado de maneira similar ao das universidades norte-americanas. O projeto era introduzir os conceitos e teorias tradicionais de Relações Internacionais, tais como realismo, idealismo, balança de poder e segurança nacional, no currículo já existente (idem). Ainda assim, o currículo manteve o seu foco em direito e história, como atesta a existência de apenas um livro sobre política internacional em língua turca durante os anos 60 , em contraposição aos vários volumes sobre direito internacional e história diplomática (Ataov, 1967:375). Isto se deu, de um lado, porque a Faculdade de Ciência Política considerava como sua missão o treinamento de burocratas de alto escalão para o Estado; de outro, porque o exame de admissão para as instituições governamentais estava centrado em conhecimentos de história e direito. Além do mais, na Turquia, as Relações Internacionais não eram consideradas parte da ciência política, mas sim um novo campo oriundo de diversas disciplinas, entre as quais estariam incluídos o direito, a história, a economia e a ciência política (Ataov, 1961). Quando outras universidades criaram departamentos de Relações Internacionais, elas seguiram o modelo adotado pela Mulkiye e organizaram seus currículos em torno dos cursos de direito e história. Ao contrário de outros contextos em que os trabalhos informados teoricamente adquiriram o mesmo 


\section{Os Estudos de Segurança na Turquia:}

Situando a Turquia no "Ocidente"...

nível que outras abordagens de Relações Internacionais (ver Smith, 2000 sobre o caso britânico), na Turquia, o estudo do direito internacional e o da história diplomática permaneceu central no estudo ${ }^{9}$ e ensino (idem; Eralp, 1996:8-9) das Relações Internacionais ${ }^{10}$.

Berdal Aral (2001), recentemente, apontou para esse vazio teórico entre os acadêmicos de Relações Internacionais na Turquia, argumentando que as Relações Internacionais eram estudadas como relações interestatais. Segundo ele, as críticas de Korany relativas à literatura sobre estudos estratégicos (negligência de aspectos econômicos, culturais e sociais das Relações Internacionais) são igualmente válidas para os escritos de acadêmicos turcos sobre as relações internacionais da Turquia (idem:186-187). Todavia, o que Aral parece não notar é que os acadêmicos turcos não estavam sozinhos em seu estadocentrismo ou em sua ênfase sobre as questões de alta política. A literatura da qual Aral é crítico fora produzida no contexto da Guerra Fria, momento em que a alta política dominava tanto a agenda acadêmica quanto política e em que os papéis desempenhados por atores não-estatais, no que tange às estratégias de moldar o processo de tomada de decisões governamental (ou quando tomando ações independentes), eram muito menos significativos se comparados aos dos dias atuais ${ }^{11}$. Em outras palavras, ao apresentar sua crítica, Aral falha ao desconsiderar o contexto histórico no qual a literatura sobre as Relações Internacionais turcas é produzida. Ele também falha ao não reconhecer o quanto a comunidade de Relações Internacionais turca (tal como as diversas outras comunidades de Relações Internacionais ao redor do mundo - ver Waever, 1998) se baseava nas falácias, bem como nos conceitos e teorias, tomados de empréstimo aos norte-americanos.

O que é mais significativo para os propósitos deste artigo é a natureza limitada da discussão sobre a parca relevância dos conceitos e teorias tradicionais ao lidarem com as inseguranças turcas, e a reduzida reflexão sobre em que medida tais inseguranças estão enraizadas nas 
características de país em desenvolvimento apresentadas pela Turquia. A questão torna-se ainda mais evidente quando analisada tendo como pano de fundo a diversidade de trabalhos produzidos, por acadêmicos provenientes do mundo em desenvolvimento, sobre a relação entre segurança e desenvolvimento (político e econômico) durante as décadas de 70 e 80 (ver, p. ex., Al-Mashat, 1985; Azar e Moon, 1988; Korany, 1986; Saravanamuttu e Thomas, 1989). Isso se deveu, parcialmente, porque, durante esse período, a análise de política externa e os estudos regionais se sobrepuseram à pesquisa teoricamente informada. De fato, até meados dos anos 60, temas de segurança eram cobertos por artigos sobre as relações internacionais tur$\operatorname{cas}^{12}$. Como veremos a seguir, a literatura das décadas de 60 e 70 sobre as políticas de segurança e defesa na Turquia adotava conceitos-padrão, sem refletir sobre seu valor explicativo dentro do contexto turco. Foi somente nos anos 80 que estudos teorizando o contexto turco começaram a aparecer.

Outra parte da razão para tão limitada discussão de cunho teórico sobre as inseguranças da Turquia, enquanto país em desenvolvimento, está assentada no contex to histórico e na orientação da política externa turca. Durante o período da Guerra Fria, a segurança turca era estudada como um aspecto da segurança "ocidental" ". Assim, enquanto as preocupações com segurança originadas fora das fronteiras nacionais (que eram comuns a outros membros da OTAN) eram reconhecidas e abordadas pela literatura, aquelas oriundas de dentro das fronteiras (que eram compartilhadas com outros países em desenvolvimento) eram tratadas com pouca atenção. Embora uma parte deste último grupo de problemas tenha sido discutida na literatura de economia (ver, p. ex., Ustunel, 1963; Basak, 1972; Tuncer, 1972), em decorrência da divisão de trabalho entre estudos de segurança e economia política (outro legado da era da Guerra Fria; ver Buzan, 1999:15; Bilgin e Morton, 2002:55-62), ela não era sempre considerada nos escritos de segurança. Durante o período da Guerra Fria, os 


\section{Os Estudos de Segurança na Turquia:}

Situando a Turquia no "Ocidente"...

escritos sobre as relações internacionais da Turquia encaravam o papel da Turquia na política mundial como de "parceira júnior" (Korany, 1986:549) dos Estados Unidos. O fato é que as representações da Turquia enquanto parceira júnior dos norte-americanos na luta contra o comunismo não só ajudaram a reproduzir a identidade ocidental turca, como também fundamentaram a produção de escritos sobre segurança na Turquia ${ }^{14}$.

O artigo de Metin Tamkoc (1961) constitui exemplo de estudo que adotou as definições-padrão de "segurança nacional" sem refletir sobre sua capacidade explicativa para o contexto turco. Nele, Tamkoc define segurança em termos externamente orientados, com ênfase em seus aspectos militares (idem:2). Sua análise descarta uma concepção de segurança orientada internamente, em especial ao explicar que a prioridade política dos primeiros anos do período republicano era buscar paz e segurança, tendo como base "principalmente a sua própria força com vistas a consolidar a pátria". Uma vez estas alcançadas, escreve Tamkoc, o objetivo das elites governantes se tornaria o de "preservar e defender a integridade territorial da Turquia bem como sua independência política contra possíveis enclaves das grandes potências a fim de subverter o status quo no Oriente Médio" (idem:13-14). A questão aqui é que, embora Tamkoc, explicitamente, adote a definição ocidental padrão de "segurança" em seu estudo, sua análise das inseguranças da Turquia mostra que uma concepção orientada internamente molda sua compreensão. Tal noção de segurança (que Tamkoc adota implicitamente) inclui preocupações com o estabelecimento da idéia de Estado na cabeça das pessoas e - ao que Buzan (1991:100-101) se refere como - a defesa da "idéia de Estado, suas instituições e seu território".

A intensificação dos problemas em Chipre durante os anos 60 levou a uma reavaliação da abordagem anterior, que mirava para a segurança da Turquia como um aspecto da segurança ocidental. Foi nesse período que análises tratando das diferenças entre as necessidades e inte- 
resses de segurança turcos e as necessidades e interesses dos aliados ocidentais começaram a emergir (Ulman, 1966). O estudo de Ulman, "Pensamentos sobre a Defesa Nacional da Turquia", é exemplar de um tipo de abordagem que apontava para as discrepâncias entre as necessidades e interesses da "segurança nacional" turca e as dos aliados ocidentais, clamando por uma diversificação das relações exteriores turcas, capaz de garantir maior autonomia em relação aos Estados Unidos. Em seu artigo, Ulman também propugnava por um repensar o interesse nacional e a segurança nacional turcas a partir de uma visão dos custos econômicos dos investimentos vinculados ao setor militar. Nesse sentido, seu trabalho constitui uma exceção à generalização feita acima acerca do declínio dos estudos que lidavam com as relações entre as dimensões econômica e militar das inseguranças da Turquia.

Ulman, que adotava uma noção mais abrangente de segurança ao integrar a dimensão econômica, não refletiu sobre as inseguranças da Turquia enquanto país em desenvolvimento. Nos anos 50 e 60, poucas tentativas foram feitas no sentido de uma teorização da experiência turca como país em desenvolvimento, localizado em região próxima a uma superpotência (União Soviética) e aliado à outra (Estados Unidos). Na verdade, ao contrário de outros países em desenvolvimento, que não sentiam a ameaça do expansionismo soviético diretamente e eram, por isso mesmo, críticos à imposição de uma agenda pelas superpotências (ver, p. ex., as colocações de Nasser, 1955), a Turquia tinha de levar em consideração tanto a ameaça soviética quanto aquelas internas ao Estado. Foram reduzidas as tentativas de teorizar essa experiência, pelos menos até o início dos anos 80 .

O trabalho de Duygu Sezer (1981), "Políticas de Segurança da Turquia", constitui o primeiro artigo teoricamente informado tratando dessa questão e representa um exemplo datado da teorização sobre a experiência turca. Ao contrário dos autores que a precederam, Sezer adota explicitamente uma noção de segurança abrangente, além de 


\section{Os Estudos de Segurança na Turquia:}

Situando a Turquia no "Ocidente"...

analisar as vulnerabilidades geradas pelas transformações socioeconômicas que a Turquia vinha atravessando através da era republicana. Segundo ela,

"[...] apesar da ausência de ameaças militares óbvias, a precariedade da condição doméstica turca a expõe ao tipo mais preciso de pressão interna e externa que poderia minar perigosamente sua capacidade de se manter de pé e de formular uma política de segurança coerente. Esta instabilidade interna é atualmente a maior fonte de insegurança para a Turquia" (idem:39).

Tais vulnerabilidades domésticas incluíam as crescentes demandas socioeconômicas da população jovem, cujas expectativas nem sempre eram atendidas pelos níveis de crescimento econômico, pelos problemas de estabilidade política doméstica, pelas sistemáticas dificuldades econômicas, pela escassez de recursos e pelo papel dos militares na política turca. Daí decorre a necessidade de focar a dimensão doméstica das inseguranças da Turquia, argumenta Sezer: "a segurança externa não pode ser alcançada sem um ambiente interno estável e um amplo grau de consenso" (ibidem).

No que tange à relação da Turquia com seus aliados ocidentais, Sezer introduz um fator alternativo: a questão do desenvolvimento. Ao contrário de trabalhos prévios que explicavam as diferenças tendo por base a singularidade da posição geográfica turca e o legado otomano, Sezer enfatiza o "elevado distanciamento entre os níveis de desenvolvimento da Turquia e dos demais membros da União Européia", como um fator que inibe a cooperação para a obtenção de armamentos. Não sendo capaz de reduzir sua dependência das importações em relação às necessidades de defesa, o dilema turco de "armas versus manteiga" era exacerbado, como ressalta a autora ${ }^{15}$.

Sezer também aponta para as inseguranças enraizadas no caráter turco de país em desenvolvimento que é ao mesmo tempo membro da OTAN. Assim, segundo a autora, a Turquia tinha de lidar "com a dupla questão do quanto ela podia destinar aos esforços de defesa em função das limitações oriundas das necessidades de desenvolvimen- 
to e quanto crédito esses limitados esforços poderiam trazer aos olhos da União Soviética e de seus aliados ocidentais" (ibidem). Sezer também explica como, durante os anos 60, sucessivos governos turcos adotaram uma concepção expansiva de segurança - entendida como a "reorientação de sua política externa quase que exclusivamente pró-ocidental para uma política mais 'multifacetada', o que significava sobretudo uma melhora nas relações com seus vizinhos e um interesse mais ativo na, bem como uma atitude mais independente para com a política mundial" (idem:30).

Dois outros importantes estudos sobre as políticas de defesa e segurança da Turquia foram publicados pelo Instituto de Política Externa (Ancara) - o mais antigo centro pensador da Turquia - nos anos 80 . Ambos tinham mais em comum com a análise de Tamkoc do que com a de Sezer, na medida em que adotavam explicitamente uma concepção de segurança orientada externamente e com foco no plano militar, enquanto a maior parte dos capítulos individuais, além da estrutura dos dois volumes, indica uma concepção de segurança internamente orientada, tal como estabelecida no pensamento dos editores e colaboradores ${ }^{16}$.

O primeiro volume editado, intitulado A Segurança da Turquia e de seus Aliados (Dis Politika Enstitusu, 1982), incluía capítulos sobre as políticas de defesa e de segurança turcas, as relações turco-norte-americanas, segurança nos flancos sudeste, mediterrâneo oriental e Golfo Pérsico, bem como a relação entre identidade e política, a ordem socioeconômica turca e o papel dos militares na política turca. O que surpreende nesse estudo é a maneira pela qual os colaboradores evitaram uma reflexão sobre a (ir)relevância da concepção tradicional de "segurança nacional" para o contexto turco, apesar de a estrutura do livro cobrir tanto aspectos internos como externos da segurança turca. Em outras palavras, embora a forma como o livro fosse estruturado desse margem a uma concepção mais abrangente de segurança, nos moldes do editorial, as contribuições individuais 


\section{Os Estudos de Segurança na Turquia:}

Situando a Turquia no "Ocidente"...

não discutiam explicitamente a questão da discrepância entre o conceito importado de "segurança nacional" e as "realidades" turcas.

O segundo volume, publicado pelo mesmo Instituto e intitulado $A$ Defesa da Turquia (Dis Politika Enstitusu, 1987), compartilha das mesmas características. Isto ocorre porque esse volume lida tanto com os aspectos internos quanto externos das inseguranças turcas, com capítulos sobre a localização geopolítica da Turquia, a percepção de ameaças e as implicações da estratégia de defesa da OTAN para a segurança turca, a estratégia de defesa turca, o orçamento de defesa, a indústria de defesa e o papel das Forças Armadas na política turca. O que é notável, pela sua ausência, é a discussão sobre os “diferentes" interesses e necessidades de segurança da Turquia enquanto país em desenvolvimento. Ademais, apesar de a maneira como o volume foi estruturado dar margem a uma compreensão mais abrangente do tema da segurança, característica dos países em desenvolvimento, nenhum reconhecimento explícito da necessidade de uma concepção diferente de segurança aplicável às inseguranças turcas foi feito. Ao contrário, o autor do capítulo "A Percepção das Ameaças da Turquia" (Tashan, 1987) é explícito em sua adoção de uma concepção de "segurança nacional" externamente orientada e militarmente focalizada. Este capítulo reflete uma perspectiva das inseguranças turcas com referência às ameaças militares à integridade territorial, ordem constitucional e interesse nacional da Turquia. Quando a questão das diferenças entre a "segurança nacional" da Turquia e aquela de seus aliados ocidentais é tratada, tais diferenças são explicadas a partir das características "singulares" da Turquia.

Recapitulando, durante a Guerra Fria, os escritos acadêmicos sobre as inseguranças turcas adotaram os conceitos e teorias "ocidentais", sem nem sempre refletirem acerca de sua relevância para o contexto turco. O reduzido número de estudos teoricamente informados é apenas uma parte da explicação. A outra está vinculada ao contexto histórico (doméstico e internacional). Durante esse período, as repre- 
sentações da Turquia como parte da estrutura de "segurança ocidental" ajudaram a situá-la no "ocidente". Isto, por seu turno, foi fundamental para moldar seus processos políticos internos - ou seja, para consolidar a Turquia enquanto democracia secular no estilo ocidental. Em um momento em que as relações de segurança constituíam a mais forte dimensão da demanda turca por uma identidade "ocidental" (Bilgin, 2003c), os escritos acadêmicos ajudaram a situar a Turquia no ocidente, por meio da representação de suas inseguranças como aspectos da segurança "ocidental”. Na ausência de um diálogo disciplinar ${ }^{17}$, os escritos sobre segurança foram moldados pelos contextos doméstico e de política externa.

\section{Parte III}

Posteriormente à reavaliação da política externa turca nos anos 60 , que se refletiu nos estudos acadêmicos sobre segurança, a subseqüente virada crítica na literatura de segurança turca aconteceu nos anos 90, quando o debate sobre a proposta turca de adesão à União Européia se intensificou (Bilgin, no prelo-a). Essa polêmica não foi meramente acadêmica já que ocorreu na arena pública - nas páginas de jornais, nas conferências públicas, bem como nos periódicos acadêmicos. Embora o número de participantes tenha permanecido limitado, dado que havia pouco questionamento público acerca da concepção de "segurança nacional" que norteara a política turca durante a Guerra Fria ${ }^{18}$, sua importância não pode ser subestimada.

Um ponto significativo de desacordo entre os envolvidos nesse debate dizia respeito às implicações da segurança para as reformas requeridas pela União Européia. Embora ambas as partes continuassem a defender a participação turca na União Européia, seus discursos divergiam no que tange à questão de qual concepção de "segurança nacional" seria mais apropriada para as políticas turcas. Enquanto alguns apontavam para a noção de "segurança nacional" como um obstáculo no caminho para a adesão à União Européia e defendiam a 


\section{Os Estudos de Segurança na Turquia:}

Situando a Turquia no "Ocidente"...

adoção de uma noção de segurança mais estreita e militarmente focalizada, outros enfatizavam as "realidades" turcas e propugnavam pela manutenção da concepção de "segurança nacional" existente (Ilhan, 2000; 2002; Manisali, 2001; 2002). O primeiro grupo era encorajado pela tentativa do então primeiro-ministro Mesut Yilmaz de iniciar o debate com a concepção de "segurança nacional"; o segundo era apoiado pela SAREM, o centro pensante das Forças Armadas turcas, que organizou uma conferência para discutir o impacto da globalização da segurança sobre a Turquia (SAREM, 2003).

Apesar de as diferenças entre a "segurança ocidental" e a "segurança nacional" turca também terem sido apontadas durante a Guerra Fria, a distinção agora estava no fato de que as diferenças eram explicadas tendo por base a natureza da Turquia enquanto país em desenvolvimento. O general Yasar Buyukanit, em seu pronunciamento de abertura à conferência da SAREM, apresentou as seguintes questões:

"Pode haver uma interseção em um mesmo eixo entre as percepções de ameaça de países poderosos e desenvolvidos e aquelas de países subdesenvolvidos e em desenvolvimento? Ou irão os países em desenvolvimento aceitar as percepções de ameaça dos países desenvolvidos incondicionalmente? Quão seguros serão os países menos poderosos cujas políticas de segurança são baseadas em percepções de ameaça importadas?

Por outro lado, quanta atenção, sensibilidade e cuidado os países poderosos devotam globalmente às percepções de ameaça reais e nacionais dos países em desenvolvimento?

Ou os países poderosos pretendem prejudicar o interesse nacional de países mais fracos pela imposição de suas próprias percepções de ameaça, definidas de acordo com seus próprios interesses nacionais?" (idem:XII, ênfases do autor).

O uso da frase "percepções de ameaça importadas" pelo general Buyukanit é importante aqui, porquanto é um reconhecimento da limitada relevância de concepções tradicionais de segurança no contexto do mundo em desenvolvimento. É também significativo, na medida em que um general das Forças Armadas da Turquia questiona aberta- 
mente se essas percepções de ameaça importadas, que, por seu turno, são baseadas em concepções de segurança importadas, são prejudiciais à segurança nacional turca. Considerando a era pregressa, em que as diferenças entre a Turquia e seus aliados ocidentais eram pouco explicitadas, a intervenção do general Buyukanit torna-se ainda mais notável. Finalmente, o discurso de Buyukanit é relevante, pois tenta justificar a manutenção da concepção existente de "segurança nacional" com referência às necessidades e interesses de segurança da Turquia, enquanto um típico país em desenvolvimento diante da globalização da segurança (e não com referência às suas preocupações singulares como ocorrera em períodos anteriores) ${ }^{19}$.

Do outro lado do debate estava um grupo de analistas que consideravam a busca pela participação na União Européia como uma questão de segurança em si mesma (Karakas, 2004; ver, também, Belge, 2003). Seus argumentos baseavam-se na pressuposição de que a concepção de segurança da União Européia se aplica ao contexto turco; se ela não se aplicar, o problema está na política turca e não no conceito de segurança da União Européia. Esta visão foi levada primeiramente a público pelo ex-primeiro-ministro Mesut Yilmaz (então vice-primeiro-ministro e ministro responsável pelas relações Turquia-União Européia), que desafiava os turcos "euro-céticos" em seus próprios termos - aqueles da "segurança nacional". Segundo Yilmaz, o problema não era só que a conceitualização turca de "segurança nacional" era por demais ampla quando comparada à dos membros da União Européia, mas também que a "segurança nacional" turca era definida a portas fechadas. O público e seus representantes tinham pouco ou nada a dizer quanto a essas definições, o que restringia sua liberdade de ação ${ }^{20}$. Yilmaz sustentou ainda que a "segurança nacional" é uma questão que preocupa a todos na Turquia e, portanto, deve ser discutida não só pelos partidos políticos, mas também pelo público em geral",21. 


\section{Os Estudos de Segurança na Turquia:}

Situando a Turquia no "Ocidente"...

Apesar de a controvérsia gerada pelo discurso de Yilmaz ter permanecido limitada em termos do número de participantes (que incluía acadêmicos, representantes de partidos políticos e atores da sociedade civil), ela foi instrumental para a clarificação das posições daqueles que até então tinham se mostrado a favor da adesão à União Européia $^{22}$. Ainda mais significativo, o passo dado por Yilmaz preparou terreno para outras articulações acerca da definição turca de "segurança nacional”.

Ao mesmo tempo que Yilmaz defendia a abertura da "segurança nacional" ao debate, um segundo desdobramento tinha vez com a emergência de um grupo de analistas que começavam a usar a linguagem da "segurança nacional" ao tratar da adesão turca à União Européia. Enquanto alguns permaneciam satisfeitos em defender que a "União Européia também seria boa para a segurança turca" (ver, p. ex., Kaleagasi, 2003), outros começaram a desenvolver um discurso alternativo sobre as necessidades e interesses de segurança da Turquia. Por exemplo, o general (aposentado) Sadi Ergüvenç criticou a concepção de segurança nacional, militarmente focalizada, que moldava as políticas turcas. Para ele, a dependência aos recursos militares poderia impedir a Turquia de alcançar a "segurança nacional", entendida como a "manutenção da liberdade e desenvolvimento em um ambiente competitivo e desregrado" (Ergüvenç, 1998:46).

O embaixador aposentado Ilter Türkmen também apontava para a ênfase concedida aos instrumentos militares como um problema e argumentava não "ser economicamente viável sustentar os atuais níveis de gasto com defesa" (Türkmen, 2001:61). A Turquia deveria aproveitar os benefícios da adesão à União Européia, segundo ele, não só econômica e politicamente, mas também em termos de segurança. A participação na União Européia, eventualmente, transformaria a cultura estratégica turca, argumentava Türkmen (ver, também, Karaosmanoglu, 2000), e melhoraria a segurança turca ao ajudar a resolver os conflitos entre Turquia e Grécia e a questão cipriota. 
Isto, por seu turno, ajudaria a estabilizar as regiões do Egeu e do Mediterrâneo e a reduzir o orçamento militar.

O que surpreende na argumentação de Ergüvenç e Türkmen é a ênfase sobre as inseguranças turcas provenientes de seu status de país em desenvolvimento (subdesenvolvimento econômico, infra-estrutura precária e escassez de recursos). As conclusões de ambos são radicalmente diferentes daquela exposta pelo general Buyukanit, favorável à manutenção da concepção de segurança nacional existente. Ao contrário, eles eram partidários da adoção de um conceito de segurança nacional mais próximo ao advogado pela União Européia, já que consideravam a participação na UE como uma política de segurança.

Durante os anos 90, o número de estudos teorizando as experiências turcas começou a crescer. Apontando para a ampliação da agenda de segurança nacional da Turquia (com a inclusão de questões de segurança tanto internas como externas) e para a convergência entre as políticas externa e de segurança nos anos 90, Ümit Cizre (1997; 2003; 2004; ver, também, Özcan, 1998; 2002) argumenta que as Forças Armadas turcas mudaram seus métodos naquela década, além de aproveitarem as oportunidades de mobilização política tornadas possíveis pela globalização para fazer incursões na sociedade turca (Cizre, 2000:4) e criar um ambiente receptivo à sua definição de "segurança nacional". Seu ponto é que os militares turcos começaram a usar a centralidade de seu papel na definição de "segurança nacional" como elemento-chave para a formulação dos processos políticos na Turquia (idem:9) e que a ampliação da agenda de segurança turca não era apenas uma estratégia em sintonia com a OTAN (o que também era ressaltado pelo chefe do staff) ${ }^{23}$, mas "refletia uma tradição particular para atentar para um papel mais ambicioso dos corpos oficiais" (idem:20; ver, também, Cizre, 2003:217-218).

Apontando para uma brecha na literatura sobre as relações civil-militares, Cizre argumenta que as políticas perseguidas pelas 


\section{Os Estudos de Segurança na Turquia:}

Situando a Turquia no "Ocidente"...

Forças Armadas turcas não podiam ser compreendidas pelos modelos existentes, que focavam o papel desempenhado pelo aparato institucional, na medida em que falhavam ao "identificar e responder a uma rede subjacente de sistemas de sustentação implícitos e muitas vezes invisíveis que legitimavam a habilidade dos militares de influenciar o processo político na Turquia" (Cizre, 2004:119).

Resumindo, desde a decisão da União Européia de 1999, diferenças dentro do grupo de analistas que se mostram favoráveis à adesão à UE têm se cristalizado. Enquanto uma facção enfatiza, cada vez mais, as implicações que a passagem e implementação das reformas requeridas pela UE provavelmente terão sobre a "segurança nacional" turca, a outra se volta diretamente para as questões de segurança, em uma tentativa de fortalecer a proposta de participação na UE. Falta ainda a emergência de um debate mais amplo sobre a definição de "segurança nacional" na Turquia entre os diferentes atores sociais (tal como aqueles da economia).

\section{Conclusão}

Como lidar com a limitada discussão na literatura de Relações Internacionais na Turquia sobre a reduzida relevância dos conceitos e teorias tradicionais de Relações Internacionais para tratar das inseguranças turcas? Este artigo procurou mostrar que isso pode ser explicado, em parte, tomando como referência a escassez de pesquisas teoricamente informadas pela análise de política externa e estudos regionais na Turquia. Durante quase todo o período da Guerra Fria, houve uma limitada reflexão sobre como e por que esses conceitos "importados" (que eram definidos nas partes conceituais dos estudos acima mencionados) não se encaixavam na discussão empírica sobre as "realidades" turcas. Nesses casos, quando as diferenças entre a Turquia e seus aliados ocidentais eram reconhecidas, poucas tentativas foram feitas com vista a teorizar as experiências turcas. Outra parte da explicação decorre do contexto histórico. Ao longo da Guer- 
Pinar Bilgin

ra Fria, a segurança turca era analisada como um aspecto da "segurança ocidental". Uma vez que a dimensão de segurança nas relações entre a Turquia e o ocidente constituía o componente mais importante da reivindicação turca de ser "ocidental", as representações nos escritos acadêmicos sobre segurança da Turquia como "parceira júnior" na luta contra o comunismo auxiliaram a situá-la dentro do "ocidente". Referidas representações também fundamentaram a produção de escritos sobre segurança na ausência de um diálogo disciplinar, que poderia ter dado à literatura turca de Relações Internacionais um perfil diferente. A questão é, portanto, que não só a política externa, mas também o contexto doméstico moldaram os escritos acadêmicos sobre a Turquia durante esse período. Uma pesquisa mais ampla sobre o estudo das Relações Internacionais no mundo em desenvolvimento é necessária para que se possa descobrir se o contexto doméstico deve ser acrescentado à lista de variáveis relevantes para a produção e pesquisa em Relações Internacionais (ver Waever, 1998).

\section{Notas}

1. Para uma tentativa recente de avaliar a relevância do construtivismo para a compreensão das políticas externas turcas, ver Bozdaglioglu (2003); sobre a relevância das abordagens críticas para o estudo das relações internacionais turcas, ver Bostanoglu (1999), Gocek (2003); sobre a política de segurança turca, ver Criss e Karaosmanoglu (s/d); Bilgin (2003b; 2003c; 2004b).

2. Para exceções a essa generalização, ver Sezer (1981) e Bolukbasi (1988).

3. A teoria do realismo subalterno de Mohammed Ayoob está assentada na concepção de Estado que deriva dos padrões históricos da Europa Ocidental. Para uma crítica, ver Barnett (2002).

4. Assim como as dimensões individual, social e global (ver Bilgin, 2003a). 


\section{Os Estudos de Segurança na Turquia: \\ Situando a Turquia no "Ocidente"...}

5. Centros temáticos foram criados nos Estados Unidos em seguida ao anúncio do programa Ponto IV (1949) do presidente Truman sobre a provisão de auxílio aos países subdesenvolvidos, momento em que os acadêmicos decidem engajar-se e produzir conhecimento sobre o mundo em desenvolvimento. Durante esse período, meia dúzia de associações sobre estudos temáticos foram criadas. Mais tarde, o Título VI do Ato Educacional da Defesa Nacional (1958) forneceu os fundos necessários para a manutenção desses centros de estudos. Para reafirmar o óbvio, as preocupações da Guerra Fria moldaram a produção de conhecimento sobre o mundo não-ocidental.

6. Note-se o paralelo com a literatura recente sobre "Estados falidos" e "Estados párias" (ver Bilgin e Morton, 2002; 2004).

7. Ver Walt (1987) para uma exceção da Guerra Fria a esta generalização. Para exemplos de teorização das experiências do Oriente Médio no pós-Guerra Fria, ver Korany et alii (1993); Barnett (1998); Lynch (1999).

8. As implicações normativas das escolhas metodológicas feitas durante esses anos permanecem pouco reconhecidas nos meios estabelecidos sobre estudos de segurança. Para uma discussão, ver Bilgin (2002).

9. Baseado em pesquisa nos principais e mais antigos jornais turcos de relações internacionais, Milletlerarasi Munasebetler Turk Yilligi/Anuário Turco de Relações Internacionais, e de ciência política, Siyasal Bilgiler Fakultesi Dergisi (ambos publicados pela Faculdade de Ciência Política, Universidade de Ancara, desde 1960 e 1946, respectivamente).

10. Os primeiros cursos de estudos regionais foram criados na Faculdade de Ciência Política em 1968-69 (Ataov, 1967:380). Estudos temáticos/regionais começaram a ganhar proeminência nos anos seguintes, com o estabelecimento de cursos sobre as políticas nos Bálcãs, Ásia Central, Oriente Médio e Sudeste Asiático. Essa mudança no currículo universitário coincidiu com o período de mudança no qual se tentava diversificar as relações exteriores da Turquia.

11. Para críticas à literatura sobre análise de política externa, ver Hey (1995) e Moon (1995).

12. Ver Soysal (1993) para uma compilação da literatura sobre política externa turca. Karaosmanoglu (1987) também aponta para o declínio nos escritos sobre segurança e defesa da Turquia.

13. Um padrão similar ocorreu com os estudos de relações internacionais em outras partes do mundo, já que, quando a questão da segurança das regiões circundantes era discutida (tal como a segurança no Mediterrâneo ou no Oriente Médio), a compreensão dos aliados ocidentais acerca de segurança regional era 
adotada (ou seja, o que região ou segurança significam era determinado por uma perspectiva orientada por atores externos e contrária àquela dos atores regionais).

14. Sobre a relação entre representação, produção de conhecimento e práticas imperialistas, ver Doty (1996).

15. Durante esse período, os países da Europa Ocidental intensificaram seus esforços para a obtenção de armamentos conjuntos, o que, por seu turno, contribuiu para a construção de uma comunidade de segurança na Europa.

16. Deve-se ressaltar que entre os colaboradores desses volumes se incluíam militares aposentados e diplomatas, bem como acadêmicos. Desnecessário dizer que o primeiro grupo não compartilhava as preocupações acadêmicas com a teorização.

17. Baseado em pesquisa nos jornais Milletlerarasi Munasebetler Turk Yilligi/Anuário Turco de Relações Internacionais, Siyasal Bilgiler Fakultesi Dergisi e Dis Politika/Política Externa (publicado pelo Instituto de Política Externa, Ancara).

18. Uma exceção a essa regra foi o debate sobre a participação da Turquia na OTAN, que aconteceu durante os anos 70, quando as relações turco-norte-americanas ficaram estremecidas pela questão cipriota (Firat, 1997:251-256). Mesmo então, o debate não questionou a definição turca de "segurança nacional”, mas sim os métodos por meio dos quais a segurança poderia ser mantida. Ver Sezer (1972:357-452) para uma análise dos debates na mídia durante os anos 60 sobre as opções de política externa turcas.

19. Como ressaltado acima, o discurso do general Buyukanit foi feito em uma conferência intitulada "Globalização e Segurança Internacional". As demais contribuições de outros participantes (em sua maioria acadêmicos turcos e estrangeiros) pareciam não refletir as visões do general acerca do gap entre os interesses e necessidades de segurança de Estados desenvolvidos e em desenvolvimento e a questão da limitada relevância das concepções ocidentais em tratar adequadamente as inseguranças do mundo em desenvolvimento. O tempo dirá se essa concepção de segurança poderá refletir-se nos escritos sobre segurança na academia.

20. Anavatan Partisi Genel Baskani Mesut Yilmazín 7. Olagan Büyük Kongre' yi Açis Konusmasi [Pronunciamento de Mesut Yilmaz ao $7^{\circ}$ Congresso $^{\circ}$ do Partido Mãe-Pátria], 4/8/2001 (disponível em http://www.anap.org.tr. Acesso em 18/7/2002). 


\section{Os Estudos de Segurança na Turquia: \\ Situando a Turquia no "Ocidente"...}

21. Trecho do Relatório da Televisão Turca TRT 2 , de 15 de agosto. BBC Monitoring International Reports (disponível em http://wwwb.business.reuters.com. Acesso em 25/7/2002). Ver Cizre (2003) para uma análise da intervenção de Yilmaz. Ver, também, Bilgin (no prelo-a) para uma análise do debate provocado pelo discurso de Yilmaz.

22. De fato, esse debate mostrou como as diferenças em torno de questões relativas à "segurança nacional" perpassavam a divisão entre "euro-céticos" e Pró-União Européia (ver Bilgin, no prelo-a).

23. “Ekonomist asker"[Economist Military Officer], Milliyet, 27/1/1998.

\section{Referências Bibliográficas}

AL-MASHAT, Abdul-Monem, M. (1985), National Security in the Third World. Boulder/London, Westview Press.

ARAL, Berdal. (2001), “Turk Dis Politikasi Soylemine Elestirel Bir Yaklasim: Turkiye-Avrupa Birligi Ortakligi”, in S. H. Calis, I. D. Dagi e R. Gozen (eds.), Turkiye'nin Dis Politika Gundemi: Kimlik, Demokrasi, Guvenlik. Ankara, Liberte, pp. 185-209.

ATAOV, Turkkaya. (1961), "Symposium on the Teaching of International Politics in Turkey”. Milletlerarasi Munasebetler Turk Yilligi, nº 2, pp. 188-196.

. (1967), "The Teaching of International Relations in Turkey". Siyasal Bilgiler Fakultesi Dergisi, vol. 22, no 4, pp. 373-383.

AYBAY, Rona. (1977), "The Role and Position of Political Science in Turkey". The Turkish Yearbook of International Relations, $\mathrm{n}^{\mathrm{0}}$ 17, pp. 13-20.

AYOOB, Mohammed. (1986), "Regional Security and the Third World", in M. Ayoob (ed.), Regional Security in the Third World; Case Studies from Southeast Asia and the Middle East. London/Sydney, Croom Helm, pp. 3-23.

. (1995), The Third World Security Predicament: State Making, Regional Conflict and the International System. Boulder, CO, Lynne Rienner. 
Pinar Bilgin

(2002), "Inequality and Theorizing in International Relations: The Case for Subaltern Realism”. International Studies Review, vol. 4, no 3, pp. 27-48.

AZAR, Edward E. e MOON, Chung-in. (1988), "Legitimacy, Integration and Policy Capacity: 'Software' Side of Third World National Security", in E. E. Azar e C.-in Moon (eds.), National Security in the Third World: The Management of Internal and External Threats. Aldershot, Edward Elgar, pp. 77-101.

BARNETT, Michael N. (1998), Dialogues in Arab Politics: Negotiations in Regional Order. New York, Columbia University Press.

(2002), "Radical Chic? Subaltern Realism: A Rejoinder". International Studies Review, vol. 4, nํ3, pp. 49-62.

BASAK, Zafer Z. (1972), “Aid, Indebtedness and Foreign Trade: The Turkish Case, 1960-1972”. Milletlerarasi Munasebetler Turk Yilligi, nº 12, pp. 78-88.

BELGE, Murat. (2003), Yaklastikça Uzaklasiyor Mu: Avrupa Birligi Ve Türkiye. Istanbul, Birikim.

BILGIN, Pinar. (2002), "Beyond Statism in Security Studies? Human Agency and Security in the Middle East". Review of International Affairs, vol. 2, nํㅗ. pp. 100-118.

. (2003a), "Individual and Societal Dimensions of Security". International Studies Review, n 5, pp. 203-222.

(2003b), “Turkiye-AB Ilisklierinde Guvenlik Kulturunun Rolu”, in C. Karadeli (ed.), Soguk Savas Sonrasinda Avrupa Ve Turkiye. Ankara, Ayrac, pp. 192-220.

(2003c), “The 'Peculiarity' of Turkey's Position on EU/NATO Military/Security Cooperation: A Rejoinder to Missiroli”. Security Dialogue, vol. 34, n- 3, pp. 345-349.

(2004a), "Whose Middle East? Geopolitical Inventions and Practices of Security". International Relations, vol. 18, no 1, pp. 17-33.

(2004b), "Clash of Cultures? Differences between Turkey and the European Union on Security”, in A. Karaosmanoglu e S. Tashan (eds.), The Europeanisation of Turkey's Security Policy: Prospects and Pitfalls. Ankara, Foreign Policy Institute. 


\section{Os Estudos de Segurança na Turquia: \\ Situando a Turquia no "Ocidente"...}

. (no prelo-a), “Turkey's Changing Security Discourses: The Challenge of

Globalisation". European Journal of Political Research.

. (no prelo-b), Regional Security in the Middle East: A Critical Approach. London, Routledge.

e MORTON, Adam David. (2002), "Historicising Representations of 'Failed States': Beyond the Cold War Annexation of the Social Sciences?'. Third World Quarterly, vol. 23, no 1, pp. 55-80.

(2004), "From 'Rogue' to 'Failed' States? The Fallacy of Short-Termism". Politics, vol. 24, no 3 .

BOLUKBASI, Suha. (1988), Superpowers and the Third World: Turkish-American Relations and Cyprus. Lanham, MD, University Press of America.

BOSTANOGLU, Burcu. (1999), Turkiye-ABD Iliskilerinin Politikasi. Ankara, Imge.

BOZDAGLIOGLU, Yucel. (2003), Turkish Foreign Policy and Turkish Identity: A Constructivist Approach. London, Routledge.

BUZAN, Barry. (1991), People, States, and Fear: An Agenda for International Security Studies in the Post-Cold War Era (2a ed.). New York, Harvester Wheatsheaf.

(1999), “'Change and Insecurity' Reconsidered”. Contemporary Security Policy, vol. 20, nº 3, pp. 1-17.

CAMPBELL, David. (1992), Writing Security: United States Foreign Policy and the Politics of Identity. Manchester, Manchester University Press.

CIZRE, Ümit. (1997), “The Anatomy of Turkish Military's Political Autonomy”. Comparative Politics, vol. 29, nº 4, pp. 151-165.

. (2000), "Politics and Military in Turkey into $21^{\text {st }}$ Century". EUI Working Papers, no 2000/24.

. (2003), "Demythologising the National Security Concept: The Case of Turkey". Middle East Journal, vol. 57, no 2, pp. 213-229.

(2004), "Problems of Democratic Governance of Civil-Military Relations and the European Union Enlargement Zone". European Journal of Political Research, vol. 43, nํำ 1, pp. 107-125. 
CRISS, Nur Bilge e KARAOSMANOGLU, Ali. (s/d), Explaining Turkey's Alignment with NATO: Realism and Culturalism. Manuscrito.

DAVID, Steve R. (1991), "Explaining Third World Alignment". World Politics, vol. $43, \mathrm{n}^{\mathrm{o}} 2$, pp. 233-256.

DIS POLITIKA ENSTITUSU. (1982), Turkiye Ve Muttefiklerinin Guvenligi. Ankara, Dis Politika Enstitusu.

(1987), Turkiye’nin Savunmasi. Ankara, Dis Politika Enstitusu.

DOTY, Roxanne Lynn. (1996), Imperial Encounters: The Politics of Representation in North-South Relations. Minneapolis, University of Minnesota Press.

ERALP, Atila (ed.). (1996), Devlet, Sistem Ve Kimlik: Uluslararasi Iliskilerde Temel Yaklasimlar. Ankara, Iletisim.

ERGÜVENÇ, Sadi. (1998), “Turkey's Security Perceptions”. Perceptions, vol. $3, \mathrm{n}^{\mathrm{o}} 2$, junho/agosto.

FIRAT, Melek. (1997), 1960-71 Arasi Türk Dis Politikasi ve Kibris Sorunu [Turkish Foreign Policy during 1960-71 and the Cyprus Problem]. Ankara, Siyasal Kitabevi.

GOCEK, Fatma Muge. (2003), “Uluslararasi Iliskilere Elestirel Yaklasim Ve Turkiye Baglami”, in A. Kaya e G. G. Ozdogan (eds.), Uluslararasi Iliskilerde Sinir Tanimayan Sorunlar. Istanbul, Baglam, pp. 109-126.

HEY, Jeanne. (1995), "Foreign Policy in Dependent States", in L. Neack, J. K. Hey e J. P. Haney (eds.), Foreign Policy Analysis: Continuity and Change in its Second Generation. New Jersey, Prentice Hall, pp. 201-213.

HOLDEN, Gerard. (2002), "Who Contextualizes the Contextualisers? Disciplinary History and the Discourse about IR Discourse". Review of International Studies, vol. 28, n 2, pp. 253-270.

HOLSTI, K. J. (1992), "International Theory and War in the Third World", in B. L. Job (ed.), The Insecurity Dilemma: National Security of Third World States. Boulder, CO, Lynne Rienner, pp. 37-60.

(1996), The State, War, and the State of War. Cambridge, Cambridge University Press. 


\section{Os Estudos de Segurança na Turquia: \\ Situando a Turquia no "Ocidente"...}

. (1998), "Scholarship in an Era of Anxiety: The Study of International Politics during the Cold War". Review of International Studies, vol. 24, noespecial, dezembro, pp. 17-46.

HUYSMANS, Jef. (2002), "Defining Social Constructivism in Security Studies: The Normative Dilemma of Writing Security". Alternatives, $\mathrm{n}^{\circ} 27, \mathrm{n}^{\circ}$ especial, pp. 41-62.

ILHAN, Suat. (2000), Avrupa Birligine Neden Hayir: Jeopolitik Yaklapim. Istanbul, Ötüken.

. (2002), Avrupa Birligine Neden Hayir: 2. Istanbul, Ötüken.

JOB, Brian L. (1992), “The Insecurity Dilemma: National, Regime and State Securities in the Third World", in B. L. Job (ed.), The Insecurity Dilemma: National Security of Third World States. Boulder, CO, Lynne Rienner, pp. 11-35.

KALEGASI, Bahadir. (2003), Avrupa Yolunun Haritasi. Istanbul, Dünya.

KARAKAS, Eser. (2004), Normallesme: Avrupa Birligi Surecinde Turkiye. Ankara, Liberte.

KARAOSMANOGLU, Ali. (1987), "Savunma Politikamizi Incelemek”, in Turkiye'nin Savunmasi. Ankara, Dis Politika Enstitusu, pp. 1-9.

. (2000), "The Evolution of the National Security Culture and the Military in Turkey”. Journal of International Affairs, vol. 54, nº 1, pp. 199-216.

KORANY, Baghat. (1986), "Strategic Studies and the Third World: A Critical Evaluation”. International Social Science Journal, vol. 38, nº 4, pp. 547-562.

NOBLE, Paul e BRYNEN, Rex (eds.). (1993), The Many Faces of National Security in the Arab World (International Political Economy Series). New York, St. Martin's Press.

LYNCH, Mark. (1999), State Interests and Public Spheres: The International Politics of Jordan's Identity. New York, Columbia University Press.

MANISALI, Erol. (2001), Yirmibirinci Yüzyilda Küresel Kiskaç: Küresellesme, Ulus Devlet Ve Türkiye. Istanbul, Otopsi.

(2002), Türkiye-Avrupa Iliskilerinde 'Sessiz Darbe' ['Silent Coupe' in Turkey-Europe Relations]. Istanbul, Derin Yayinlari. 
MITCHELL, Timothy. (2003), "Deterritorialization and the Crisis of Social Science", in A. Mirsepassi, A. Basu e F. Waever (eds.), Localizing Knowledge in a Globalizing World: Recasting the Area Studies Debate. Syracuse, Syracuse University Press, pp. 148-170.

MOON, Bruce E. (1995), “The State in Foreign and Domestic Policy”, in L. Neack, J. K. Hey e J. P. Haney (eds.), Foreign Policy Analysis: Continuity and Change in its Second Generation. New Jersey, Prentice Hall, pp. 187-200.

MUPPIDI, Himadeep. (1999), "Postcoloniality and the Production of International Insecurity: The Persistent Puzzle of U.S.-Indian Relations", in J. Weldes et alii (eds.), Cultures of Insecurity: States, Communities and the Production of Danger. Minneapolis, University of Minnesota Press, pp. 119-146.

NASSER, Gamal Abdel. (1955), “The Egyptian Revolution”. Foreign Affairs, vol. 32, nº 2, pp. 199-211.

Ó TUATHAIL, Gearóid e DALBY, Simon. (1998), "Introduction: Rethinking Geopolitics, Towards a Critical Geopolitics", in G. Ó Tuathail, S. Dalby e P. Routledge (eds.), The Geopolitics Reader. London, Routledge.

ÖZCAN, Gencer. (1998), "Doksanlarda Türkiye'nin Ulusal Güvenlik ve Dis Politikasinda Askeri Yapinin Artan Etkisi" ["The Increasing Influence of the Military Structure on Turkey's National Security and Foreign Policies during the 1990s"], in G. Özcan e S. Kut (eds.), En Uzun Onyil: Türk Dis Politikasinda Doksanli Yillar [The Longest Decade: The Nineties in Turkish Foreign Policy]. Istanbul, Boyut, pp. 67-100.

. (2002), "The Military and the Making of Foreign Policy in Turkey", in B.

Rubin e K. Kirisçi (eds.), Turkey in World Politics: An Emerging Multiregional Power. Istanbul, Bogazaiçi University Press, pp.18-41.

PASHA, Mustapha Kamal. (1996), "Security as Hegemony”. Alternatives, vol. $21, \mathrm{n}^{\circ} 3$, pp. 283-302.

SARAVANAMUTTU, Paikiasothy e THOMAS, Caroline. (1989), Conflict and Consensus in South/North Security (Ford/Southampton Studies in North/South Security Relations). Cambridge, Cambridge University Press.

SAREM. (2003), Kuresellesme Ve Uluslararasi Guvenlik: Birinci Uluslararasi Sempozyum Bildirileri. Ankara, Genelkurmay Basim Evi.

SAYIGH, Yezid. (1990), "Confronting the 1990s: Security in the Developing Countries". Adelphi Articles, nº 251. 


\section{Os Estudos de Segurança na Turquia: \\ Situando a Turquia no "Ocidente"...}

SEZER, Duygu. (1972), Kamu Oyu ve Dis Politika. Ankara, A.U.S.B.F.

(1981), “Turkey’s Security Policies”. Adelphi Articles, no 164.

SMITH, Mark J. (1998), Social Science in Question. London, Sage.

SMITH, Steve. (2000), "The Discipline of International Relations: Still an American Social Science?'. British Journal of Politics and International Relations, vol. 2, nº 3, pp. 374-402.

SOYSAL, Ismail. (1993), Turk Dis Politikasi Incelemeleri Icin Kilavuz. Istanbul, ISIS.

TAMKOC, Metin. (1961), “Turkey's Quest for Security through Defensive Alliances". Milletlerarasi Munasebetler Turk Yilligi, nº 2, pp. 1-39.

TASHAN, Seyfi. (1987), “Turkiye'nin Tehdit Algilamalari”, in Turkiye'nin Savunmasi. Ankara, Dis Politika Enstitusu pp. 32-40.

TAYFUR, Fatih. (1999), "Turkish Foreign Policy towards the Euro-Mediterranean Partnership and the Black Sea Economic Cooperation: A Comparative Analysis”. Foreign Policy (Ankara), vol. 23, nº 1-2-3-4.

TAYLOR, Peter. (1996), "Embedded Statism and the Social Sciences Opening up to New Spaces". Environment and Planning A, vol. 28, n11, pp. 1917-1929.

THOMAS, Caroline. (1987), In Search for Security: The Third World in International Security. Boulder/London, Wheatsheaf.

(1989), “Conclusion: Southern Instability, Security and Western Concepts - On an Unhappy Marriage and the Need for a Divorce", in C. Thomas e P. Saravanamuttu (eds.), The State and Instability in the South. New York, St. Martin's Press, pp. 174-191.

TICKNER, Arlene B. (2003), "Hearing Latin American Voices in International Relations Studies”. International Studies Perspectives, vol. 4, nº 4, pp. 325-350.

TICKNER, J. Ann. (1997), “You Just don't Understand: Troubled Engagements between Feminists and IR Theorists". International Studies Quarterly, $\mathrm{n}^{\circ}$ 41, pp. 611-632.

TUNCER, Baran. (1972), “The Impact of Foreign Private Investments of the Turkish Economy”. Milletlerarasi Munasebetler Turk Yilligi, $\mathrm{n}^{\mathrm{o}} 12$.

TÜRKMEN, Ýlter. (2001), “Güvenlik, Ekonomi Ve Dis Politika”. Foreign Policy (Turkey), Mart-Nisan, pp. 58-65. 
Pinar Bilgin

ULMAN, Haluk. (1966), “Turk Ulusal Savunmasi Uzerine Dusunceler”. Siyasal Bilgiler Fakultesi Dergisi, vol. 21, nº 4, pp. 197-226.

USTUNEL, Besim. (1963), "Western Regionalism and Developing Countries”. Milletlerarasi Munasebetler Turk Yilligi, nº 4, pp. 63-80.

WAEVER, Ole. (1995), “Securitization and Desecuritization”, in R. D. Lipschutz (ed.), On Security. New York, Columbia University Press, pp. 46-86.

(1998), "The Sociology of a Not so International Discipline: American and European Developments in International Relations". International Organization, vol. 52, no 4, pp. 687-727.

WALT, Stephen M. 1987. The Origins of Alliances. Ithaca, Cornell University Press.

\section{Resumo}

\section{Os Estudos de Segurança na Turquia: Situando a Turquia no "Ocidente" por meio de "Escrever a Segurança"}

A concepção de segurança nacional orientada externamente e focada militarmente não lida suficientemente bem com as inseguranças turcas, inseguranças estas compartilhadas com outros países em desenvolvimento. Apesar disso, durante toda a Guerra Fria, houve pouca discussão acerca da limitada relevância de tais conceitos e teorias tradicionais das Relações Internacionais para tratar das inseguranças turcas. $\mathrm{O}$ artigo procura explicar este fato fazendo referência à preocupação política prevalecente no período, qual seja, a de situar a Turquia no "Ocidente". Os trabalhos acadêmicos sobre segurança nesse período, sugere o artigo, ajudaram a situar a Turquia no "Ocidente" mediante a representação de suas preocupações como aspectos da segurança “ocidental”, e não como preocupações típicas de países em desenvolvimento. O ponto é que, ao longo da Guerra Fria, as representações da Turquia como "parceira júnior" dos Estados Unidos na luta contra o comunismo não só ajudaram a reproduzir sua identidade "ocidental", mas também embasaram os escritos sobre segurança na Turquia. O artigo está dividido em três partes. A primeira discute o problema da disjunção entre os conceitos e teorias de Relações Internacionais e as "realidades" do mundo em desenvolvimento, enfatizando a importância do contexto histórico para 


\section{Os Estudos de Segurança na Turquia:}

Situando a Turquia no "Ocidente"...

a compreensão de por que e como conceitos e teorias viajam entre mundos. A segunda parte analisa de que maneira a questão da irrelevância dos conceitos e teorias tradicionais foi tratada pela literatura de Relações Internacionais turca durante a Guerra Fria. A terceira analisa os debates da década de 90 sobre a concepção turca de "segurança nacional".

Palavras-chave: Estudos de Segurança - Segurança - Turquia - Identidade - Teoria/Prática

\section{Abstract}

\section{The Study of Security in Turkey: Locating Turkey in the "West" through "Writing Security"}

The externally oriented and military-focused conception of national security does not fare well when accounting for the insecurities Turkey has shared with other developing countries. Yet, throughout the Cold War era, there was little discussion on the limited relevance of such standard concepts and theories of International Relations when accounting for Turkey's insecurities. The article seeks to explain this with reference to a prevalent policy concern of the time: locating Turkey firmly in the "West". Scholarly writings on security during this period, the article suggests, helped to locate Turkey in the "West" through representing its concerns as aspects of "Western" security - but not as concerns typical to developing countries. The point being that throughout the Cold War, representations of Turkey as a "junior partner" of the United States in the fight against communism not only helped to (re)produce its "Western" identity but also underlay the production of writings on security in Turkey. The article falls into three parts. Part I discusses the issue of misfit between International Relations concepts and theories and "realities" of the developing world and emphasises the significance of historical context for understanding why and how theories and concepts travel between worlds. Part II looks at how the issue of the (ir)relevance of standard concepts and theories was treated in Turkey's International Relations literature during the Cold War. Part III looks at the 1990s debates on Turkey's conception of national security.

Key words: Security Studies - Security - Turkey - Identity Theory/Practice 